\title{
First Report on Molecular Diagnosis and Phylogenetic Analysis of Hepatozoon canis in Naturally Infected Domesticated and Stray Dogs from Jhang, Pakistan
}

\author{
Mazhar Abbas ${ }^{1}$, Amar Nasir $^{1 * \dagger}$, Syed Ehtisham-ul-Haque ${ }^{2}$, Muhammad Kashif $^{1}$, Muhammad Arfan Zaman ${ }^{2}$, Arbab \\ Sikandar $^{3}$ and Muhammad Avais ${ }^{4}$ \\ ${ }^{1}$ Department of Clinical Sciences, Sub-campus Jhang, University of Veterinary and Animal Sciences, Lahore 54000, Pakistan \\ ${ }^{2}$ Department of Pathobiology, Sub-campus Jhang, University of Veterinary and Animal Sciences, Lahore 54000, Pakistan \\ ${ }^{3}$ Department of Basic Sciences, Sub-campus Jhang, University of Veterinary and Animal Sciences, Lahore 54000, Pakistan \\ ${ }^{4}$ Department of Veterinary Medicine, University of Veterinary and Animal Sciences, Lahore 54000, Pakistan \\ *For correspondence: amar.nasir@uvas.edu.pk \\ Received 21 January 2021; Accepted 27 March 2021; Published 10 June 2021
}

\begin{abstract}
Canine diseases, particularly caused by tick-borne hepatozoons are responsible for high morbidity and mortality and are the reason for attracting significant focus. The current study was aimed to survey the occurrence of $H$. canis in domesticated and stray dogs of Jhang city (Punjab) with its molecular identification. For this, blood samples from 300 dogs ( $\mathrm{n}=200$ domesticated; $\mathrm{n}=100$ stray) were collected and assayed through PCR for the detection of $H$. canis supported by sequencing analysis. The results demonstrated, $15.66 \%$ (47/300) of samples positive for $H$. canis. A significantly $(\mathrm{P}<0.05)$ higher occurrence of $H$. canis was observed in stray dogs $(27 \%)$ than domesticated dogs $(10 \%)$. Evaluation of the various risk factors showed that the age, sex, breed, dog category (domestic or stray), body coat, environmental settings (rural or urban) and ectoparasitic infestation were significantly $(P<0.05)$ associated with the occurrence of infection. The phylogenetic analysis of the PCR confirmed specimens revealed a very close homology of the detected strains with the ones diagnosed earlier in China and Malta. It was concluded that present moderate prevalence of $H$. canis among the dog populations in the area of Jhang may rise with stray dogs being most vulnerable hosts and potential source of vectors spread. (C) 2021 Friends Science Publishers
\end{abstract}

Keywords: H. canis; PCR and phylogenetic analysis; Prevalence; Stray dogs

\section{Introduction}

Canine hepatozoonosis is a tick-borne disease of carnivores affecting both the wild and domestic animals. More than 300 hepatozoon species have been known so far, out of which 46 infect mammals. Hepatozoon spp. belonging to phylum hepatozoid apicomplexa are the blood parasites of vertebrate intermediate hosts (Baneth et al. 2003). These intracellular protozoans affect the leukocytes chiefly neutrophils and monocytes of animals (Baneth 2011). Hepatozoon canis (H. canis) and Hepatozoon americanum (H. americanum) are the two reported species acting as sole source of infection among dogs (Baneth et al. 2000). $H$. canis is the cause of Old World canine hepatozoonosis and has been transmitted by Amblyomma ovale (Forlano et al. 2005; Rubini et al. 2009), Haemaphysalis (H.) longicornis, H. flava (Murata et al. 1995) and Rhipicephalus sanguineus sensu lato (Baneth et al. 1998). Epidemiological studies have reported the prevalence of $H$. canis in Asia, Europe, Southeast Asia, Africa, Middle East and South America, while $H$. americanum has been limited to the United States (Ewing and Panciera 2003). H. americanum can only be transmitted by Amblyomma maculatum and has been found in the Central and South American countries (VincentJohnson 2003).

Pathogenesis of $H$. canis is considered relatively weaker as subclinical infections are predominant, manifesting milder disease affecting the spleen, lymph nodes, and bone marrow, culminating in anemia and lethargy (Baneth and Weigler 1997). Transplacental transmission of $H$. canis is possible (Murata et al. 1993). Infection can be diagnosed by PCR or sequencing (Baneth et al. 2003; Criado-Fornelio et al. 2007). Only a limited studies on $H$. canis have been reported in Pakistan till to date (Qamar et al. 2017; Ahmad et al. 2018). It was hypothesized that $H$. canis is prevalent in the dogs of this region and the current study was planned to investigate the prevalence and risk factors associated with the protozoon infection in domestic and stray dogs from Jhang, Punjab, Pakistan. It is one of the very few studies exploring the

To cite this paper: Abbas M, A Nasir, S Ehtisham-ul-Haque, M Kashif, MA Zaman, A Sikandar, M Avais (2021). First report on molecular diagnosis and phylogenetic analysis of Hepatozoon canis in naturally infected domesticated and stray dogs from Jhang, Pakistan. Intl J Agric Biol 26:17-21 
phylogenetic sequence of $18 \mathrm{~S}$ rRNA gene of $H$. canis in domestic and stray dogs from Pakistan, providing baseline information for effective control of this malady in dogs.

\section{Materials and Methods}

\section{Study area and blood sampling}

Blood samples $(\mathrm{n}=300)$ were collected randomly from 03 different dog breeds i.e.; German Shepherd $(\mathrm{n}=100)$, Pointer $(\mathrm{n}=100)$ and non-descript stray dogs $(\mathrm{n}=100)$ from Jhang, Pakistan. About $5 \mathrm{~mL}$ of blood was collected aseptically from cephalic or saphenous venipuncture using $5 \mathrm{~mL}$ disposable plastic syringe. The collected blood samples were immediately transferred to purple capped vacutainer (BD Vacutainer ${ }^{\circledR}$ spray-coated $\mathrm{K}_{2}$ EDTA) tubes and appropriately labeled. Subsequently, the samples were transported in cold chain to Postgraduate Medicine Laboratory at College of Veterinary and Animal Sciences (CVAS), Jhang for initial analysis, and were preserved at $-20^{\circ} \mathrm{C}$ till the DNA was extracted. The study design was permitted by the Committee on Animal Ethics at CVAS (Sub-campus University of Veterinary \& Animal Sciences, Lahore), initially with the final approval of the content by Directorate of Advanced Studies (DAS/7550, on 23 July 2019) of the University. Verbal and written consents were acquired by each dog owner prior to blood sampling of their animals. Data pertaining to possible contributing risk factors such as age (evaluated the age via canine teeth and incisor changes), sex, breed, dog category either domestic or stray, environmental settings (rural or urban) and ectoparasite control practices were collected using a predesigned questionnaire proforma.

\section{Molecular detection}

The extraction of genomic DNA of protozoan (H. canis) was carried out from $200 \mu \mathrm{L}$ of EDTA anticoagulated blood specimens using a commercially available QIAamp DNA Mini Kit (QIAGEN GmbH, Hilden, Germany) as per manufacturer's instructions. The quality of DNA was measured by electrophoresis on an agarose gel. The primers PIRO-A1(50-AGGGAGCCTGAGAGACGGCTACC-30) and PIROB (50-TTAAATACGAATGCCCCCAAC-30) (manufactured by Gene Link ${ }^{\mathrm{TM}}$ ) were used to amplify an approximately $450 \mathrm{bp}$ region of the $18 \mathrm{~S}$ rRNA gene (Földvári et al. 2005). PCR was performed in a total of 25 $\mu \mathrm{L}$ volume of reaction mixture having $12 \mu \mathrm{L}$ Master mix (VizPure ${ }^{\mathrm{TM}}$ PCR $2 \mathrm{X}$ Master), $2 \mu \mathrm{L}$ forward and reverse primers each, $4 \mu \mathrm{L}$ of DNA and $5 \mu \mathrm{L}$ of nuclease free water.

The PCR amplification was accomplished in a thermal cycler (Applied Biosystems ${ }^{\circledR}$ Veriti $^{\circledR}$, Foster city, California). The initial denaturing temperature was set at $95^{\circ} \mathrm{C}$ for 10 min with subsequent 40 cycles at $94^{\circ} \mathrm{C}$ for 30 sec, annealing at $59^{\circ} \mathrm{C}$ for $30 \mathrm{sec}$, extension at $72^{\circ} \mathrm{C}$ for 30 $\mathrm{sec}$ and the final extension was obtained at $72^{\circ} \mathrm{C}$ after $7 \mathrm{~min}$.
The amplified DNA (Fig. 1) was examined through 1.3\% agarose gel electrophoresis. A 100 bp marker was also run to ascertain the size of amplified DNA (Thermo Scientific ${ }^{\circledR}$, Waltham, Massachusetts).

\section{Sequencing and phylogenetic analysis}

For the confirmation of PCR results, a total of 10 randomly selected samples were subjected to sequencing, out of which 4 were recognized as $H$. canis. The PCR selected products were cleaned up using a commercial kit method. For DNA sequencing reaction, Big Dye ${ }^{\circledR}$ Terminator v3.1 Cycle Sequencing Kit (Perkin-Elmer, Applied Biosystems ${ }^{\circledR}$ Division) was used. For examination of sequencing reactions, ABI Prism ${ }^{\circledR}$ 3730xl Genetic Analyzer (Applied Biosystems $^{\circledR}$, Foster city, California) was used. The sequences obtained were checked with Chromas v.1.45 and compared to sequence data available in the GenBank1, using the BLAST at NCBI (http://www.ncbi.nlm.nih.gov/BLAST/). The newly identified sequences of the partial 18S rRNA gene of $H$. canis identified in the current study were submitted to GenBank (Accession numbers: MN900602, MN900603, MN900610 and MN900692).

The phylogenetic analysis was completed using the software MEGA X 10.0.5 to compare the DNA sequences of the current study with the ones previously deposited in the GenBank from the studies conducted in the other countries. The neighbor-joining algorithms using the Tamura 3 Parameter trees were formulated. Nodes with bootstrap values of greater than $30 \%$ after 1,000 replicates are indicated (Fig. 2).

\section{Statistical analysis}

The data pertaining to prevalence of $H$. canis among dogs were analyzed using Pearson Chi Square statistic at 95\% confidence interval using the OpenEpi program (https://www.openepi.com/TwobyTwo/TwobyTwo.htm).

\section{Results}

Overall, $15.66 \%(47 / 300, \pm 4.1$ at $95 \% \mathrm{CI})$ of the samples amplified exhibited 450-bp band specific for 18S rRNA gene of $H$. canis. Analysis of the possible risk factors associated with $H$. canis occurrence was carried out using Chi-square statistics (Table 1) It showed that the prevalence of $H$. canis was significantly $(P<0.05)$ associated with various risk factors, namely, age, sex, breed, dog category (domestic or stray), body coat, environmental (rural or urban) settings and ectoparasitic infestation. The prevalence was high in the males and young dogs of age below one year with long body coat and dogs kept in the rural areas. The male dogs depicted relatively higher prevalence $(P<$ $0.05)$ than females. The stray or abandoned dogs infested with ticks represented a significantly $(P<0.05)$ higher 
Molecular and Phylogenetic Analysis of Hepatozoon canis in Dogs / Intl J Agric Biol, Vol 26, No 1, 2021

Table 1: Descriptive statistics and results of a Chi-square testing for the association between selected potential risk factors and $H$. canis prevalence (at $95 \% \mathrm{CI}$ )

\begin{tabular}{|c|c|c|c|c|c|}
\hline Risk Factors & Category & Samples Tested (n) & Positive (n) & $\%$ prevalence & $P$-value \\
\hline \multirow[t]{2}{*}{$\overline{\text { Age }}$} & $<1$ Year & 166 & 34 & 20.48 & 0.010 \\
\hline & $>1$ Year & 134 & 13 & 9.70 & \\
\hline \multirow[t]{2}{*}{ Sex } & Male & 214 & 40 & 18.69 & 0.022 \\
\hline & Female & 86 & 7 & 8.13 & \\
\hline \multirow[t]{3}{*}{ Breed } & German Shepherd & 100 & 14 & 14 & 0.003 \\
\hline & Pointer & 100 & 8 & 8 & \\
\hline & Non-descript & 100 & 25 & 25 & \\
\hline \multirow[t]{2}{*}{ Dog Category } & Pet Dogs & 200 & 20 & 10 & 0.000 \\
\hline & Stray Dogs & 100 & 27 & 27 & \\
\hline \multirow[t]{2}{*}{ Body Coat } & Long & 207 & 40 & 19.32 & 0.009 \\
\hline & Short & 93 & 7 & 7.52 & \\
\hline \multirow[t]{2}{*}{ Environmental setting } & Urban & 193 & 23 & 11.91 & 0.016 \\
\hline & Rural & 107 & 24 & 22.42 & \\
\hline \multirow[t]{2}{*}{ Ectoparasitic infestation } & Yes & 185 & 35 & 18.91 & 0.049 \\
\hline & No & 115 & 12 & 10.43 & \\
\hline
\end{tabular}

$\mathrm{P}$ values $\leq 0.05$ are statistically significantly different

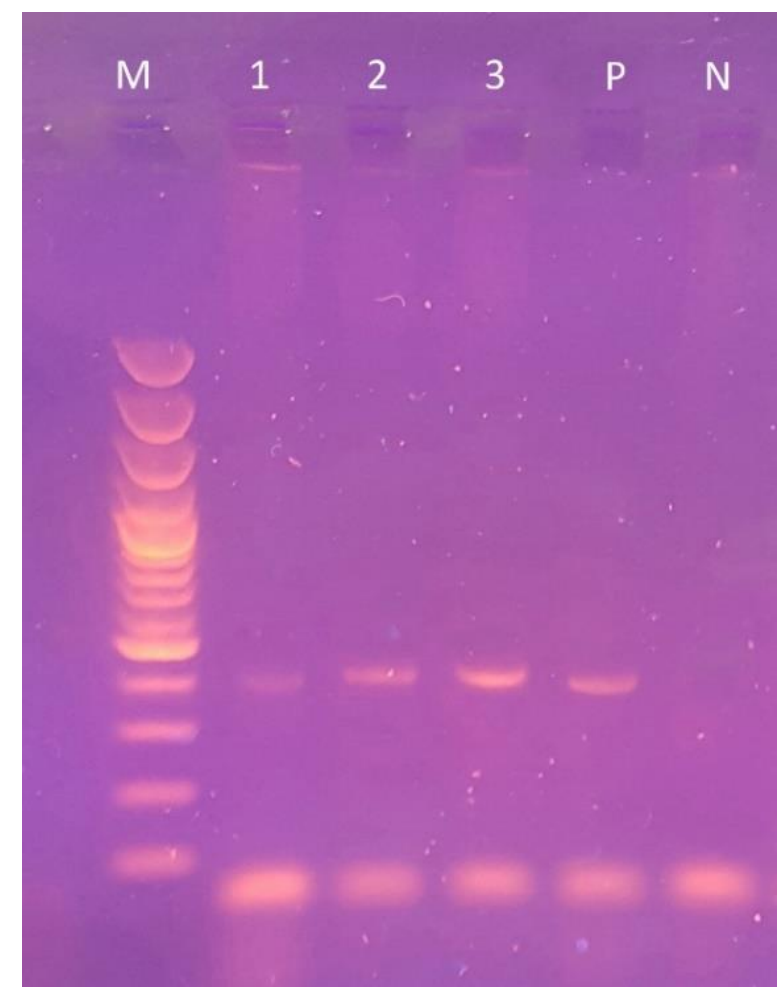

Fig. 1: PCR amplification of 450 bp of $18 \mathrm{~S}$ rRNA represent $H$. canis, Lane 1-3 represents $H$. canis samples $\mathrm{M}=100$ bp DNA ladder/marker, $\mathrm{P}=\mathrm{Control}$ positive and $\mathrm{N}=\mathrm{Control}$ negative

prevalence than the domestic dogs kept as pets by the owners irrespective of their area of living i.e., either in rural or urban ambiance.

A total of 10 PCR amplicons were randomly sorted out for performing the DNA sequencing. The outcome of sequencing of the amplicon displayed 4 distinct 18S rRNA sequences (466-496bp). The nucleotide BLAST analysis confirmed the similarity among the obtained sequences at large (i.e., sequence homology $>92 \%$ ) to already existing $H$. canis spp. in the data bases. The alignment of 4 confirmed

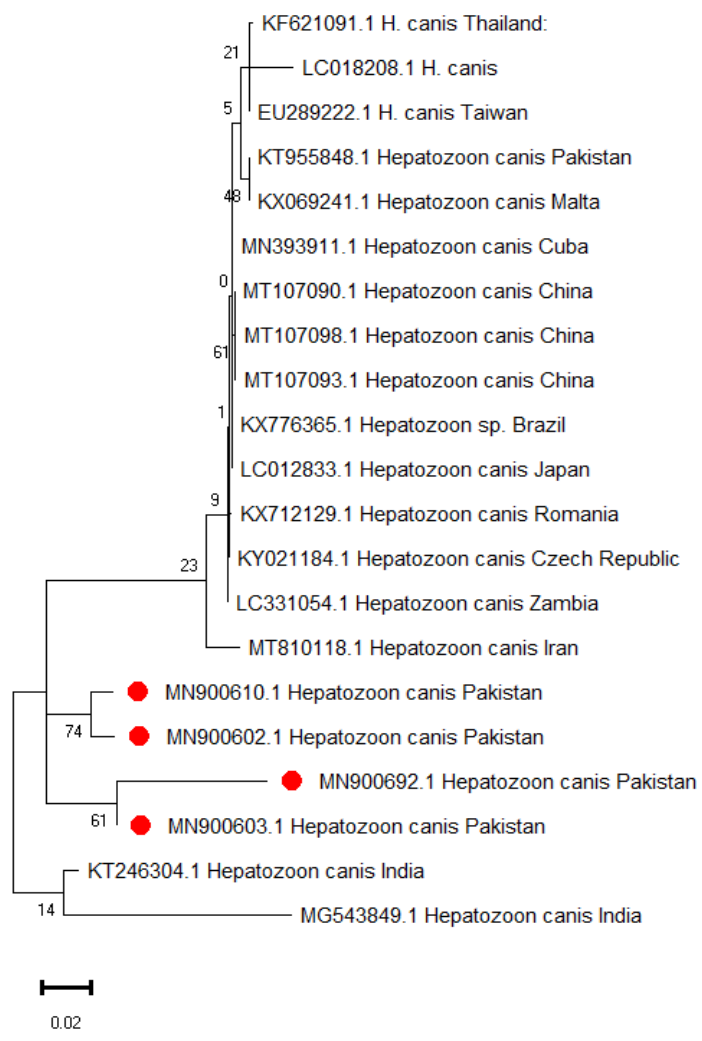

Fig. 2: Phylogenetic relationship of $H$. canis detected during present study to $H$. canis (red dots) reported from other countries based on the partial sequence of the 18S rRNA gene. The evolutionary history was inferred by the Neighbor-Joining method based on the Tamura-Nei mode. Boot strap analysis, used to estimate the node reliability of the trees, was conducted with 1000 replicates as implemented in MEGA X 10.0.5. Hepatozoon spp., host species, country of origin from where these sequences were derived and the GenBank accession numbers are included for each sequence

sequences was submitted to GenBank (GenBank accession numbers MN900602, MN900603, MN900610 and MN900692). 


\section{Discussion}

The current study enabled the first insight of the genetic characterization of $H$. canis from domesticated and stray dogs in the oldest district of Jhang, Punjab (Pakistan). Canine hepatozoonosis is a tick-borne disease of increasing importance in dogs worldwide. Besides the microscopic and serological methods of diagnosis, molecular techniques are quite specific and sensitive. In the current study, dogs reared in the Jhang district were investigated showing a prevalence of $15.66 \%$. The prevalence of $H$. canis recorded in the current study was significantly $(P<0.05)$ higher than an earlier study in Pakistan (Qamar et al. 2017) reporting a prevalence of $11.9 \%$ but lower than $45.5 \%$ Ahmad et al. (2018). This variation in the prevalence of $H$. canis may be attributed to many factors, including the distribution (Spolidorio et al. 2009), population status of the vector (Otranto et al. 2011), methodology of sampling and the traits of the dog population being studied (de Azevedo Gomes et al. 2016). The differences of environmental settings either rural or urban, the status of look after extended by the owner to their pets and a stray category in the present study of dogs were observed as the significantly contributing risk factors in the incidence of this infection.

Surveys of $H$. canis in dogs in different countries have shown varying prevalence rates such as Brazil $3.8 \%$, Croatia 11.8\% (Vojta et al. 2009), Costa Rica 7.5\% (Rojas et al. 2014), India 30\% (Singla et al. 2016), Iran 23\% (Dalimi et al. 2017), Qatar 1.6\% (Alho et al. 2017), Thailand 11.4\% (Jittapalapong et al. 2006) and Turkey 3.6\% (Aydin et al. 2015). The prevalence recorded in the present study also lies in between the highest and lowest prevalence of 3.6\% and $30 \%$. However, further broad studies are required to make the scenario clearer.

Contrarily, some of the investigations from Brazil have reported alarmingly high prevalence (58.7 and 66.4\%) of $H$. canis in dogs ( Spolidorio et al. 2009; de Castro Demoner et al. 2016). The variations in the reported prevalence may plausibly be owing to various risk factors including the traits of the target dog population under investigation, season of specimens collection, social and husbandry facilities (same species animals and tick preventive measures), geoclimatic characteristics influencing the abundance and spread of tick vector species (Stich et al. 2014).

As far as the role of various risk factors in the prevalence of canine hepatozoonsis is concerned, many of authors have reported higher prevalence among young dogs under the age of one year than older ones (Abdullahi et al. 1990; Vezzani et al. 2017) resembling with the findings of the current study. This may be due to deficient immune competency and vulnerable exposure of infection at young age. In pertinence to dogs' categories as pets or stray, a significantly higher $(P<0.05)$ prevalence among stray dogs was encountered than their pet counterparts. The most plausible reason in this scenario seems to be the keen observation and vigilance of domestic dogs by the owners contrary to the sheer abandonment of ownership on the part of stray dogs. The stray dogs wander here and there having maximum chances of getting tick infestation and subsequent infection (Bashir et al. 2009). It has been also seen that contact with other animals (domestic or wild) can pose a high risk of tick infestation. Stray dogs have been mostly infected with vector borne diseases than other pet breeds (Hornok et al. 2006; Amuta et al. 2010; Singh et al. 2014).

In terms of sex of the host, male dogs were found to be affected significantly $(P<0.05)$ high than females being in consensus with a previous report (Vezzani et al. 2017). Male dogs, owing to their wandering, aggressive and fighting temperament seem to be affected higher while the females have been observed to remain isolated after mating during the term and post-whelping in fostering the pups. Here, it was seen that contact with other animals may be the source of transmission as the other livestock animals at the farm may already have tick load. Anyhow, this risk factor was not evidenced as a significant contributor possibly because the animals coming in contact with these dogs were either free of ticks or were least exposed owing to good management. Dog category either pet or stray was significantly $(P<0.05)$ different in current study, and also is not in line with the findings of previous studies which may possibly be due to difference in the breeds as the susceptibility to the disease may be associated with the breed genetics.

As the coat of body is concerned, it was noted that dogs with long coat are more susceptible than short coated dogs. In the current study it was seen that environmental setting influences the prevalence of $H$. canis as the dogs in rural areas are more infected than the urban areas. The livestock population is significantly high in the rural areas and in contact dogs may get the ticks transferred from other animals and become the source of infection to nearby dogs as described by (Pacifico et al. 2020). The ticks attached hide themselves in long coat and remain unnoticed from the owner's observation. This is the very first report of molecular detection and characterization of $H$. canis in naturally infected dogs (pet and stray dogs) from Jhang, Pakistan.

\section{Conclusion}

In conclusion, the prevalence of $H$. canis among the dog populations is considerable with a potential to rise with soaring trends of dog keeping in the region. PCR coupled with sequencing analysis provides a reliable confirmatory test for such emerging infections in the non-reported areas for undertaking effective therapeutic and control measures.

\section{Acknowledgements}

Authors are highly indebted to Mr. Majid Ali Nasir for assisting in the collection of blood samples and Dr. Nasrullah Khan for analyzing the data. Lab consumables were purcahsed from a research Project No. PARB 660 2018 being executed in the discipline of Parasitology of College of Veterinary and Animal Sciences, Jhang-Pakistan. 


\section{Author Contributions}

MA AN and AS planned the experiments; SEH and MAZ interpreted the results; MK statistically analyzed the data and made illustrations; MA contributed in the write up.

\section{Conflict of interest}

The authors declare no conflict of interest.

\section{Data Availability}

Data presented in this study will be available on a fair request to the corresponding author

\section{Ethics Approval}

Not applicable in this paper

\section{References}

Abdullahi S, A Mohammed, A Trimnell, A Sannusi, R Alafiatayo (1990). Clinical and haematological findings in 70 naturally occurring cases of canine babesiosis. J Small Anim Pract 31:145-147

Ahmad AS, MA Saeed, I Rashid, K Ashraf, W Shehzad, RJ Traub, G Baneth, A Jabbar (2018). Molecular characterization of Hepatozoon canis from farm dogs in Pakistan. Parasitol Res 117:1131-1138

Alho AM, C Lima, MS Latrofa, V Colella, S Ravagnan, G Capelli, LM de Carvalho,LCardoso, D Otranto (2017). Molecular detection of vectorbornepathogensindogsand cats from Qatar.Parasit Vect 10; Article 298

Amuta E, B Atu, R Houmsou, J Ayashar (2010). Rhipicephalus sanguineus infestation and Babesia canis infection among domestic dogs in Makurdi, Benue State-Nigeria. Intl J Acad Res 2:170-172

Aydin MF, F Sevinc, M Sevinc (2015). Molecular detection and characterization of Hepatozoon spp. in dogs from the central part of Turkey. Ticks Tick Borne Dis 6:388-392

Baneth G, B Weigler (1997). Retrospective case-control study of hepatozoonosis in dogs in Israel. $J$ Vet Intern Med 11:365-370

Baneth G, V Shkap, M Samish, E Pipano, I Savitsky (1998). Antibody response to Hepatozoon canis in experimentally infected dogs. Vet Parasitol 74:299-305

Baneth G, JR Barta, V Shkap, DS Martin, DK Macintire, N VincentJohnson (2000). Genetic and antigenic evidence supports the separation of Hepatozoon canis and Hepatozoon americanum at the species level. J Clin Microbiol 38:1298-1301

Baneth G, JS Mathew, V Shkap, DK Macintire, JR Barta, SA Ewing (2003). Canine hepatozoonosis: Two disease syndromes caused by separate Hepatozoon spp. Trends Parasitol 19:27-31

Baneth G (2011). Perspectives on canine and feline hepatozoonosis. Vet Parasitol 181:3-11

Bashir I, Z Chaudhry, S Ahmed, M Saeed (2009). Epidemiological and vector identification studies on canine babesiosis. Pak Vet J 29:51-54

Criado-Fornelio A, C Rey-Valeiron, A Buling, J Barba-Carretero, R Jefferies, $P$ Irwin (2007). New advances in molecular epizootiology of canine hematic protozoa from Venezuela, Thailand and Spain. Vet Parasitol 144:261-269

Dalimi A, F Jameie, A Mohammadiha, M Barati, S Molaei (2017). Molecular detection of Hepatozoon canis in dogs of Ardabil Province, Northwest of Iran. Archive Rizvi Instit 72:197-201

de Azevedo Gomes L, PHG Moraes, LDCS do Nascimento, LH O'Dwyer, MRT Nunes, ADRP Rossi, DCF Aguiar, EC Gonçalves (2016). Molecular analysis reveals the diversity of Hepatozoon species naturally infecting domestic dogs in a northern region of Brazil. Tick Tick Borne Dis 7:1061-1066 de Castro Demoner, Larissa, NM Magro, MRL da Silva, JM Azevedo, de Paula Antunes, CIP Calabuig, L O’Dwyer (2016). Hepatozoon spp. infections in wild rodents in an area of endemic canine hepatozoonosis in southeastern Brazil. Tick Tick Borne Dis $7: 859-864$

Ewing SA, R Panciera (2003). American canine hepatozoonosis. Clin Microbiol Rev 16:688-697

Földvári G, E Hell, R Farkas (2005). Babesia canis canis in dogs from Hungary: Detection by PCR and sequencing. Vet Parasitol 127:221-226

Forlano M, A Scofield, C Elisei, K Fernandes, S Ewing, C Massard (2005). Diagnosis of Hepatozoon spp. in Amblyomma ovale and its experimental transmission in domestic dogs in Brazil. Vet Parasitol 134:1-7

Hornok S, R Edelhofer, R Farkas (2006). Seroprevalence of canine babesiosis in Hungary suggesting breed predisposition. Parasitol Res 99:638-642

Jittapalapong S, O Rungphisutthipongse, S Maruyama, JJ Schaefer, RW Stich (2006). Detection of Hepatozoon canis in stray dogs and cats in Bangkok, Thailand. Ann NY Acad Sci 1081:479-488

Murata T, M Inoue, S Tateyama, Y Taura, S Nakama (1993). Vertical transmission of Hepatozoon canis in dogs. J Vet $\mathrm{Med} \mathrm{Sci}$ 55:867-868

Murata T, M Inoue, Y Taura, S Nakama, H Abe, K Fujisaki (1995). Detection of Hepatozoon canis oocyst from ticks collected from the infected dogs. $J$ Vet Med Sci 57:111-112

Otranto D, F Dantas-Torres, S Weigl, MS Latrofa, D Stanneck, D Decaprariis, G Capelli, G Baneth (2011). Diagnosis of Hepatozoon canis in young dogs by cytology and PCR. Parasit Vector 4:1-6

Pacifico L, J Braff, F Buono, M Beall, B Neola, J Buch, G Sgroi, D Piantedosi, M Santoro, P Tyrrell (2020). Hepatozoon canis in hunting dogs from Southern Italy: Distribution and risk factors. Parasitol Res 119:3023-3031

Qamar M, MI Malik, M Latif, Q Ain, M Aktas, RS Shaikh, F Iqbal (2017). Molecular detection and prevalence of Hepatozoon canis in dogs from Punjab (Pakistan) and hematological profile of infected dogs. Vector Borne Zoonotic Dis 17:179-184

Rojas A, D Rojas, V Montenegro, R Gutiérrez, D Yasur-Landau, G Baneth (2014). Vector-borne pathogens in dogs from Costa Rica: First molecular description of Babesia vogeli and Hepatozoon canis infections with a high prevalence of monocytic ehrlichiosis and the manifestations of co-infection. Vet Parasitol 199:121-128

Rubini A, K Paduan, T Martins, M Labruna, L O'dwyer (2009). Acquisition and transmission of Hepatozoon canis (Apicomplexa: Hepatozoidae) by the tick Amblyomma ovale (Acari: Ixodidae). Vet Parasitol 164:324-327

Singh A, H Singh, N Singh, N Singh, J Rath (2014). Canine babesiosis in northwestern India: Molecular detection and assessment of risk factors. Bio Med Res Intl Article 741785

Singla LD, D Sumbria, A Mandhotra, M Bal, P Kaur (2016). Critica analysis of vector-borne infections in dogs: Babesia vogeli, Babesia gibsoni, Ehrlichia canis and Hepatozoon canis in Punjab, India. Acta Parasitol 61:697-706

Spolidorio MG, MB Labruna, AM Zago, DM Donatele, KM Caliari, NH Yoshinari (2009). Hepatozoon canis infecting dogs in the State of Espírito Santo, southeastern Brazil. Vet Parasitol 163:357-361

Stich RW, BL Blagburn, DD Bowman, C Carpenter, MR Cortinas, SA Ewing, D Foley, JE Foley, H Gaff, GJ Hickling, RR Lash, SE Little, C Lund, R Lund, TN Mather, GR Needham, WL Nicholson, J Sharp, AV Stokes, D Wang (2014). Quantitative factors proposed to influence the prevalence of canine tick-borne disease agents in the United States. Parasti Vector 7; Article 417

Vezzani D, CF Scodellaro, DF Eiras (2017). Hematological and epidemiologicalcharacterization of Hepatozoon canis infection in dogs from Buenos Aires, Argentina. Vet Parasitol Reg Stud Rep 8:90-93

Vincent-Johnson NA (2003). American canine hepatozoonosis. Vet Clin North Am Small Anim Pract 33:905-920

Vojta L, V Mrljak, S Ćurković, T Živičnjak, A Marinculić, R Beck (2009). Molecular epizootiology of canine hepatozoonosis in Croatia. Intl $J$ Parasitol 39:1129-1136 